\section{Effect of production process and high-pressure processing on viability of Salmonella spp. in traditional Italian dry-cured coppa}

\author{
Roberta Taddei, ${ }^{1}$ Federica Giacometti, ${ }^{2}$ \\ Lia Bardasi, ${ }^{1}$ Paolo Bonilauri, ${ }^{3}$ \\ Mattia Ramini, ${ }^{1}$ Maria Cristina \\ Fontana, ${ }^{1}$ Patrizia Bassi, ${ }^{1}$ \\ Sara Castagnini, ${ }^{1}$ Francesco Ceredi, ${ }^{1}$ \\ Maria Francesca Pelliconi, ${ }^{1}$ \\ Andrea Serraino, ${ }^{2}$ Federico Tomasello, ${ }^{2}$ \\ Silvia Piva, ${ }^{2}$ Elisabetta Mondo, ${ }^{2}$ \\ Giuseppe Merialdi ${ }^{1}$ \\ ${ }^{1}$ Istituto Zooprofilattico Sperimentale \\ delle Lombardia e dell'Emilia Romagna, \\ Sede Territoriale di Bologna; \\ ${ }^{2}$ Dipartimento di Scienze Mediche \\ Veterinarie, Università di Bologna, \\ Ozzano dell'Emilia (BO); ${ }^{3}$ Istituto \\ Zooprofilattico Sperimentale delle \\ Lombardia e dell'Emilia Romagna, Sede \\ Territoriale di Reggio Emilia, Reggio \\ nell'Emilia, Italy
}

\begin{abstract}
The aim of the study was to investigate the combined effect of the manufacturing process followed by HPP treatment on the inactivation of Salmonella spp. in artificially contaminated coppa samples, in order to verify the ability of the combined processes to achieve the objective of a $5-\log$ reduction of Salmonella spp. needed for exportation to the U.S. Fresh anatomical cuts intended for coppa production were supplied by four different delicatessen factories located in Northern Italy. Raw meat underwent experimental contamination with Salmonella spp. using a mixture of 3 strains. Surface contamination of the fresh anatomical cuts was carried out by immersion into inoculum containing Salmonella spp. The conditions of the HPP treatment were: pressure 593 $\mathrm{MPa}$, time 290 seconds, water treatment temperature $14^{\circ} \mathrm{C}$. Surface and deep samples were performed post contamination (T0), end of the cold phase (T1), end of process (Tend), and after HPP treatment (postHPP) and Salmonella spp. Enumerated. The results of this study show a significant reduction of Salmonella spp. all through the production process $(\mathrm{P}<0.01)$ for all companies, followed by an additional reduction of bacterial counts due to HPP treatment $(\mathrm{P}<0.01)$, both in superficial and deep contaminations $(\mathrm{P}<0.01)$. The superficial overall reduction resulted of 1.58 to $5.04 \log \mathrm{CFU} / \mathrm{g}$ during the
\end{abstract}

production process. HPP treatment resulted in a significant $(\mathrm{P}<0.01)$ superficial and deep decrease in Salmonella spp. enumeration varying from 0.61 to $4.01 \mathrm{log}$ and from 1.49 to $4.13 \mathrm{log}$. According to the data presented in this study, only the combined approach of coppa manufacturing process followed by HPP treatment always led to a 5-log reduction of Salmonella spp. required by USDA/FSIS guidelines.

\section{Introduction}

Coppa is a typical Italian cured pork meat product obtained from the cervical muscles of the neck of heavy pigs. The traditional areas of production are the provinces of Parma and Piacenza (Emilia Romagna region, Northern Italy), however it is produced with different recipes in many other Italian regions. Few data exist in literature on the characteristics and on product processing and the most relevant information can be found in the PDO specifications

(http://www.salumidoppiacentini.com/coppa -d-

$\mathrm{p} /$ index.jspeldoc IdC $=160 \& \mathrm{IdS}=168 \&$ tipo cliccato $=0 \&$ tipo $\_$padre $=0 \&$ nav $=1 \&$ css $=$ gen erico_dop.css\&menu $=1$;

http://www.coppadiparmaigp.com/disciplina re-di-produzione-igp-coppa-parma/) or in the few published papers (Busconi et al., 2014; Zanardi et al., 2000). Coppa is a product consisting of a whole piece of meat, whose manufacturing process includes some peculiar phases. After deboning, half-slicing, and trimming the anatomical cut, salting is carried out: a mixture of salt, additives, and spices is distributed all over the meat, the composition of the ingredients varies according to the tradition and the recipes of production. Meat is then massaged manually or by a meat tumbling machine in order to ensure the homogeneous distribution of the mixture. Generally, one or two salting processes are carried out and followed by storage at low temperatures for a few days on steel trays (cold rest). At the end of the rest period, the meat cuts are wrapped in natural or synthetic casings, tied with a string, and then hung for several days in a drying chamber where they are exposed to higher temperatures and lower relative humidity, in order to reduce moisture. Finally, the ripening takes place for several weeks at a lower temperature and higher relative humidity than drying, until the product reaches the desired characteristics. Dry-cured meat products contamination by food-borne pathogens as Salmonella spp. and L. monocytogenes may result from superficial contamination of the fresh
Correspondence: Andrea Serraino, Dipartimento di Scienze Mediche Veterinarie - Università di Bologna, Via Tolara di Sopra n. 50, 40064 Ozzano dell'Emilia (BO), Italy. Tel.: +390512097323

E-mail: andrea.serraino@unibo.it

Key words: dry cured meat products, HPP, Salmonella spp.

Contributions: The authors contributed equally.

Conflict of interest: The authors declare no conflict of interest.

Funding: None.

Received for publication: 25 July 2019.

Revision received: 7 January 2020.

Accepted for publication: 8 January 2020.

This work is licensed under a Creative Commons Attribution-NonCommercial 4.0 International License (CC BY-NC 4.0).

(C) Copyright: the Author(s), 2020

Licensee PAGEPress, Italy

Italian Journal of Food Safety 2020; 9:8445

doi:10.4081/ijfs.2020.8445

anatomical cuts. It can occur both during slaughtering and production and/or from cross-contamination in case of manipulation by contaminated operators or contact with contaminated equipment or surfaces.

Both EU and U.S. regulation requires ready-to-eat (RTE) meat products to be free from Salmonella (European Commission 2005; Todd et al.; 2004, FSIS 2017). In addition, Salmonella Compliance Guidelines for small and very small meat and poultry establishments that produce RTE products (FSIS, 2017) recommended that enterprises producing RTE meat must validate their processes in order to achieve at least a 5-log reduction of Salmonella spp. (FSIS, 2017). Establishments most often achieve the target by cooking, but they can use other lethality treatments such as fermentation, drying, salt curing, alternative processing technologies or a combination of these (FSIS, 2017); the same requirement is due for exportation of meat products to the U.S. (Italian Ministry of Health, 2015).

High hydrostatic pressure (HPP) is a non-thermal food preservation technology applied to enhance the microbiological safety and to extend the shelf life of the treated food while keeping the organoleptic and nutritional characteristics unaltered. HPP has been considered to be the main emergent preservation technology with more prospects for its application in the meat industry (Hugas et al., 2002); it is mainly 
used as a final sanitization measure after production and/or packaging procedures. HPP has been successfully applied for the treatment of a wide variety of food such as jams, fruit sauces, yogurt, beef, fruit and vegetable juices, processed poultry products, oysters, cheese and carpaccio (Tao et al., 2016). Several treated RTE dry-cured meat products such as ham and salami are currently available on the market in Europe, U.S.A., Japan, Canada (Tao et al., 2016).

The aim of the present study was to investigate the combined effect of the manufacturing process followed by HPP treatment on the inactivation of Salmonella spp. in artificially contaminated coppa samples, in order to verify the ability of the combined processes to achieve the objective of a 5-log reduction of Salmonella spp. needed for exportation to the U.S.

\section{Materials and Methods}

\section{Inoculum composition}

The Salmonella spp. inoculum culture was prepared using a mixture of 3 strains: 118174/1 (monophasic $S$. Typhimurium) isolated from fresh pork sausage, 106463/1 $(S$. Derby) isolated from fresh swine meat, and the reference strain $S$. Typhimurium ATCC 14028 according to Bonilauri et al. (2019). $100 \mu 1$ of a stock culture (stored in $20 \%$ glycerol at $-80^{\circ} \mathrm{C}$ ), each strain was transferred to $10 \mathrm{ml}$ Brain Heart Infusion (BHI) broth and incubated for $24 \mathrm{~h}$ at $30^{\circ} \mathrm{C}$. Subsequently, an aliquot of $100 \mu \mathrm{l}$ was transferred to $1000 \mathrm{ml} \mathrm{BHI}$ broth and incubated at $30^{\circ} \mathrm{C}$ for $72 \mathrm{~h}$ to reach the stationary phase.

Just before the use, the 3 subcultures of Salmonella spp. were combined in equal volume (one liter each) in order to obtain a multi-strain cocktail of about 109 colony forming units $(\mathrm{CFU}) / \mathrm{ml}$ and the resulting mixed culture was checked by enumeration on selective agar.

\section{Samples contamination and produc- tion process}

Fresh anatomical cuts intended for coppa production were supplied by four different small delicatessen factories located in Northern Italy herein named A, B, C and D. Raw meat (weight between 2.5 and $3 \mathrm{~kg}$ ) underwent experimental contamination with Salmonella spp. Surface contamination of the fresh anatomical cuts was carried out by immersion into inoculum containing Salmonella spp. The immersion lasted for 10 minutes and was followed by drying for dripping at room temperature for 30 minutes.

The four production processes were carried out in IZSLER laboratories following the producers' standard protocols as summarized in Table 1. One (company A and D) or two salting (companies B and C) were comprised, salting mixtures being supplied by the four companies. In all the protocols meat samples underwent one or more steps in the meat tumbling machine in order to get a homogenous distribution of the salting mixture. After the salting step, coppa samples were singularly packed in synthetic casings and at the end of the maturation period, were separately transferred to nylonpolyethylene bags and vacuum sealed. Coppa samples underwent processing steps according to the producer's specification (see Table 1): a resting phase (14 to 32 days at $1-8^{\circ} \mathrm{C}$ ), a drying phase ( 3 to 7 days at 12 $20^{\circ} \mathrm{C}$ ), and a ripening phase (40 to 69 days at $14-18^{\circ} \mathrm{C}$ ).

\section{HPP treatment}

For each contamination study, 5 vacuum-packed coppa samples were exposed to HPP treatment and 5 samples acted as control. The level of contamination before HPP was 1.56 - 5.09 log CFU/g in the superficial samples and $1.60-3.06 \mathrm{log}$ CFU/g in the deep samples (see Table 2 Tend values). The conditions of the HPP treatment were: pressure $593 \mathrm{MPa}$, time 290 seconds, water treatment temperature $14^{\circ} \mathrm{C}$, product temperature during treatment $4^{\circ} \mathrm{C}$ (Bonilauri et al., 2019). The pressure-holding treatment time in this study did not include the pressure increase time or the decompression time. The water temperature during the process started from $14^{\circ} \mathrm{C}$, grew until $32^{\circ} \mathrm{C}$ during the treatment, and immediately returned to $14^{\circ} \mathrm{C}$ after the end of pressure stress.

\section{Sampling procedure}

The protocol of this study included both analysis on the surface and in depth of coppa samples. For superficial sampling, three squares with a length of approximately $3 \times 3$ $\mathrm{cm}$ and a thickness of about $0.3 \mathrm{~cm}$ enough to get a final weight of $25 \mathrm{~g}$, were excided from apical, central and terminal positions of each coppa. Deep sampling was carried out after immersion of coppa samples in boiling water for 60 seconds. A sample unit of $25 \mathrm{~g}$ from the depth of coppa was then extracted.

\section{Physicochemical analysis}

$a_{\mathrm{w}}$ was measured with AcquaLab, series

Table 1. Main characteristics of the three production processes reproduced in this study.

\begin{tabular}{|c|c|c|c|c|}
\hline & Company A & Company B & Company C & Company D \\
\hline Anatomic cut weight (Kg) & 2,7 & 2,5 & 3 & $2,5 / 3$ \\
\hline Number of salting & 1 & 2 & 2 & 1 \\
\hline Resting length (days)/temperatures & $14 / 3-5^{\circ} \mathrm{C}$ & $32 / 3-5^{\circ} \mathrm{C}$ & $27 / 1-4^{\circ} \mathrm{C}$ & $9 / 6-8^{\circ} \mathrm{C}$ \\
\hline Drying length (days)/temperatures & $5 / 20^{\circ} \mathrm{C}$ & $7 / 27^{\circ} \mathrm{C}$ to $14^{\circ} \mathrm{C}$ & $6 / 22^{\circ} \mathrm{C}$ to $16^{\circ} \mathrm{C}$ & $3 / 12-27^{\circ} \mathrm{C}$ \\
\hline Ripening length (days)/temperatures & $51 / 15^{\circ} \mathrm{C}$ & $40 / 14-18^{\circ} \mathrm{C} \quad 24 / 17-21^{\circ} \mathrm{C}$ & $69 / 14-16^{\circ} \mathrm{C}$ & $44 / 14^{\circ} \mathrm{C}$ to $16^{\circ} \mathrm{C}$ \\
\hline
\end{tabular}

Table 2. Experimental scheme including the number of analyzed test units for each processing step, sampling characteristics and scheduled analyses.

\begin{tabular}{lllll} 
Sampling time & Processing step & Test units & Type of Sampling & Analysis \\
T0 & Post-contamination & 3 & Superficial & Salmonella spp. enumeration, pH, $a_{\mathrm{w}}$ \\
T1 & Post-resting & 3 & Superficial - In deep & Salmonella spp. enumeration, pH, $a_{\mathrm{w}}$ \\
Tend & Post-ripening & 5 & Superficial - In deep & Salmonellaspp. enumeration, $\mathrm{pH}, a_{\mathrm{w}}$ \\
THPP & Post-HPP treatment & 5 & Superficial - In deep & Salmonella spp. enumeration \\
\hline
\end{tabular}


4, Model TE instrument, in accordance with ISO 21807:2004. The $\mathrm{pH}$ values were determined with Mettler Toledo LE427 glass electrode probe attached to pHenomenal PC5000 L (VWR) pH/conductivity meter. Weight loss values (expressed as percentage of the initial weight) were determined throughout the production process, on three samples for each contamination study.

\section{Microbiological analysis}

Salmonella spp. enumeration, samples were $1 / 10$ diluted and homogenized in Stomacher for $60 \mathrm{~s}$. Ten-fold serial dilutions were pour-plated onto XLD agar and incubated at $37^{\circ} \mathrm{C}$ for $24 \mathrm{~h}$. Suspected colonies were identified using MicrogenTM GN-ID (GNA, Microgen Bioproducts. Ltd., UK). In samples below the quantification limit of 10 Colony Forming Units (CFU)/g, the qualitative analysis was carried out according to ISO 6579:2002/Cor 1:2004 (ISO, 2004).

\section{Data analysis}

According to EFSA (2010), for statistical analysis, if Salmonella spp. was detectable by the presence/absence test but not quantifiable in enumeration analysis (under the limit of quantification: $\mathrm{LOQ}=10$ $\mathrm{CFU} / \mathrm{g}$ ) the value of $9 \mathrm{CFU} / \mathrm{g}$ (corresponding to $\log _{10} 9=0.95 \log \mathrm{cfu} / \mathrm{g}$ ) was assigned. If Salmonella spp was no detectable by the presence/absence test, the value of 0.03 $\mathrm{CFU} / \mathrm{g}$ was assigned (corresponding to less than 1 cell on $25 \mathrm{~g}$ ); $\log 100.03=-1.52 \log$ $\mathrm{CFU} / \mathrm{g}$ ). To compare the level of pathogens observed during processing steps and post HPP treatment, the two-way ANOVA test was chosen; level 1 was Company productive process (A, B, C, D) and level 2 was productive phases post contamination (T0), end of the resting phase (T1), end of ripening phase (Tend), and after HPP treatment (postHPP). When statistically significant differences were detected, oneway ANOVA and post hoc pairwise comparison across levels were performed by using Tukey's test. Surface and deep contaminations were compared separately.

The statistical analyses were performed by using the computer software program STATA 7.0 (STATA Corporation, College Station, TX, USA). Significance was established at $\mathrm{p}<0.05$.

\section{Results and Discussion}

The four production processes were characterized by different numbers of salting, cold and warm phase lengths and temperatures (Table 1) resulting in dry-cured coppa with different physicochemical characteristics ( $a_{\mathrm{w}}$ ranging from 0.892 to $0.922, \mathrm{pH}$ ranging from 5.66 to 6.61 on the surface and $a_{\mathrm{w}}$ ranging from 0.916 to 0.925 , $\mathrm{pH}$ ranging from 5.61 to 6.13 in the deep part as reported in Table 3 ). The $\mathrm{pH}$ trend was in line with reported variability (5.5-6.5) cited by the PDO Product specification for coppa Piacentina

(http://www.salumidoppiacentini.com/coppa
-d-p/index.jspeldoc?IdC=160\&IdS=168\&tipo cliccato $=0 \&$ tipo padre $=0 \&$ nav $=1 \&$ css $=$ gener ico_dop.css\&menu=1)Artificial contamination gained at a superficial initial concentration ranging from 6.52 to $7.47 \mathrm{log} \mathrm{CFU} / \mathrm{g}$ of Salmonella spp. (Table 4). A contamination of the inoculated bacteria from the surface to the depth of the anatomical cuts was shown, probably facilitated by the use of the meat tumbling machine in concomitance with salting. In particular at the end of cold progressing phases deep contamination was first examined and reached values comprised among 4.10 to $4.84 \log$ CFU/g of Salmonella spp.

The results of this study show a significant reduction of Salmonella spp. all through the production process $(\mathrm{P}<0.01)$ for all companies, followed by an additional reduction of bacterial counts due to HPP treatment $(\mathrm{P}<0.01)$, both in superficial and deep contaminations $(\mathrm{P}<0.01)$, in accordance with several other dry-cured meat products in which Salmonella spp. decrease resulted equal to 3.28 and $5.5 \log$ in pork loins (Morales-Partera et al., 2017) and ham after 69 days of curing (Reynold et al., 2001) respectively, the observed differences were mainly due to different product characteristics and different production processes.

In detail, the superficial overall reduction resulted of 1.58 to $5.04 \log \mathrm{CFU} / \mathrm{g}$ during the production process, being 4.66$5.04 \log$ CFU/g for Company A, B and C and significantly lower (1.58 log CFU/g

Table 3. Results of chemico-physical analysis differentiated for manufacturing company carried out in superficial (Sup) and deep (Deep) samples: it is reported the mean value of the obtained measurements followed by the standard deviation into brackets.

\begin{tabular}{|c|c|c|c|c|c|c|c|c|c|c|c|c|c|c|c|c|}
\hline & \multicolumn{4}{|c|}{ Company A } & \multicolumn{4}{|c|}{ Company B } & \multicolumn{4}{|c|}{ Company C } & \multicolumn{4}{|c|}{ Company D } \\
\hline & $\mathrm{pH}_{\text {Sup }}$ & $a_{\text {wSup }}$ & $\mathrm{pH}_{\text {Deep }}$ & $a_{\text {wDeep }}$ & $\mathrm{pH}_{\text {Sup }}$ & $a_{\text {wSup }}$ & $\mathrm{pH}_{\text {Deep }}$ & $a_{\text {wDeep }}$ & $\mathrm{pH}_{\text {Sup }}$ & $a_{\text {wSup }}$ & $\mathrm{pH}_{\text {Deep }}$ & $a_{\text {wDeep }}$ & $\mathrm{pH}_{\text {Sup }}$ & $a_{\text {wSup }}$ & $\mathrm{pH}_{\text {Deep }}$ & $a_{\text {wDeep }}$ \\
\hline T0 & $5.95(0.07)$ & $0.997(0.001)$ & N.D. & N.D. & $6.40(0.12)$ & $0.997(0.001)$ & N.D. & N.D. & $5.99(0.25)$ & $0.994(0.002)$ & N.D. & N.D. & $5.93(0.12)$ & $0.995(0.002)$ & N.D. & N.D. \\
\hline $\mathrm{T} 1$ & $6.04(0.10)$ & $0.959(0.009)$ & $6.03(0.16)$ & $0.979(0.01)$ & $6.20(0.18)$ & $0.933(0.008)$ & $5.92(0.12)$ & $0.973(0.005)$ & $5.86(0.13)$ & $0.964(0.038)$ & $5.62(0.15)$ & $0.972(0.002)$ & $5.54(0.03)$ & $0.974(0.004)$ & $5.73(0.14)$ & $0.976(0.006)$ \\
\hline Tend & $5.66(0.18)$ & $0.892(0.017)$ & $5.61(0.13)$ & $0.924(0.01)$ & $6.61(0.23)$ & $0.922(0.005)$ & $6.13(0.16)$ & $0.925(0.006)$ & $6.05(0.19)$ & $0.904(0.019)$ & $5.80(0.05)$ & $0.916(0.010)$ & $5.98(0.12)$ & $0.913(0.005)$ & $5.76(0.09)$ & $0.923(0.004)$ \\
\hline
\end{tabular}

Table 4. Mean value log cfu/g (standard deviation) of Salmonella spp. (S) enumeration analyses carried out in superficial (Sup) and deep (Deep) Samples.

\begin{tabular}{|c|c|c|c|c|c|c|c|c|}
\hline & \multicolumn{2}{|c|}{ Company A } & \multicolumn{2}{|c|}{ Company B } & \multicolumn{2}{|c|}{ Company C } & \multicolumn{2}{|c|}{ Company D } \\
\hline & $S_{\text {Sup }}$ & $S_{\text {Deep }}$ & $S_{\text {Sup }}$ & $S_{\text {Deep }}$ & $S_{\text {Sup }}$ & $S_{\text {Deep }}$ & $S_{\text {Sup }}$ & $S_{\text {Deep }}$ \\
\hline T0 & $6.60^{\mathrm{A}}(0.22)$ & N.D. & $7.35^{\mathrm{A}}(0.18)$ & N.D. & $6.52^{\mathrm{A}}(0.25)$ & N.D. & $7.47(0.02)$ & N.D. \\
\hline $\mathrm{T} 1$ & $5.38^{\mathrm{B}, \mathrm{x}}(0.27)$ & $4.80^{\mathrm{A}, \mathrm{x}}(0.80)$ & $5.32^{\mathrm{B}, \mathrm{x}}(0.33)$ & $4.84^{\mathrm{A}, \mathrm{x}}(0.12)$ & $4.85^{\mathrm{B}, \mathrm{x}}(0.27)$ & $4.10^{\mathrm{A}, \mathrm{x}}(0.44)$ & $4.81(0.87)$ & $4.71(0.97)$ \\
\hline Tend & $1.56^{\mathrm{C}, \mathrm{x}}(0.56)$ & $2.61^{\text {B,y }}(0.20)$ & $2.49^{\mathrm{c}, \mathrm{x}}(0.27)$ & $1.95^{\mathrm{B}, \mathrm{x}}(0.70)$ & $1.86^{\mathrm{C}, \mathrm{x}}(1.22)$ & $1.60^{\mathrm{B}, \mathrm{x}}(0.37)$ & $5.89(1.05)$ & $3.06(1.20)$ \\
\hline THPP & $0.95(0.00)$ & $-1.52(0.00)$ & $-0.04(1.36)$ & $0.46(1.11)$ & $0.95(0.00)$ & $-0.53(1.35)$ & $1.88(0.60)$ & $-1.03(1.11)$ \\
\hline
\end{tabular}

ND: Not Determined; \# assumed value: 0.95 when in all replicates pathogen was detected but not countable $<10 \mathrm{CFU} / \mathrm{g},-1.52$ when in all replicates pathogen is not detected, -0.04 when in 3 out of 5 replicates pathogen was detectable but not countable and the last two were not detected, -0.53 when in 2 out of 5 replicates pathogen was detectable but not countable and the last three were not detected, 0.46 when in 4 out of 5 replicates pathogen was detectable but not countable and the last one was not detected, -1.03 when in 1 out of 5 replicates pathogen was detectable but not countable and in 4 replicates were not detected; when assumed value is used no statistical comparison was possible. Different capital letter significant differences between results in different rows. $x, y$ means differences between surface and deep contamination in rows. Differences between Companies were not significant (see text). 
Table 5. Logarithmic unit reductions of Salmonella spp. (S) in superficial samples after each sampling step.

\begin{tabular}{|c|c|c|c|c|c|c|c|c|}
\hline & \multicolumn{2}{|c|}{ Company A } & \multicolumn{2}{|c|}{ Company B } & \multicolumn{2}{|c|}{ Company C } & \multicolumn{2}{|c|}{ Company D } \\
\hline & $S_{\text {Sup }}$ & $S_{\text {Deep }}$ & $S_{\text {Sup }}$ & $S_{\text {Deep }}$ & $S_{\text {Sup }}$ & $S_{\text {Deep }}$ & $S_{\text {Sup }}$ & $S_{\text {Deep }}$ \\
\hline Resting - $\Delta(\mathrm{T} 0-\mathrm{T} 1)$ & 1.22 & N.D. & 2.03 & N.D. & 1.67 & N.D. & 2.66 & N.D. \\
\hline Drying and Ripening - $\Delta$ (T1-Tend $)$ & 3.82 & N.D. & 2.83 & N.D. & 3.02 & N.D. & -1.08 & N.D. \\
\hline Production process - $\Delta(\mathrm{T} 0-\mathrm{Ten} d)$ & 5.04 & N.D. & 4.86 & N.D. & 4.69 & N.D. & 1.58 & N.D. \\
\hline HPP - $\Delta$ (Tend-THPP) & 0.61 & 4.13 & 2.53 & 1.49 & 0.88 & 2.13 & 4.01 & 4.09 \\
\hline TOTAL - $\triangle(\mathrm{T} 0-\mathrm{T} H P P)$ & 5.65 & N.D. & 7.39 & N.D. & 5.57 & N.D. & 5.59 & N.D. \\
\hline
\end{tabular}

reduction) for company $\mathrm{D}$ (see Table 5); for company D a noticeable shorter duration of all the phases was observed; it was reported that Salmonella count reduction during seasoning is related not only to $a_{\mathrm{w}}$ reached at the end of the process but in particular to the duration of seasoning (Pin et al., 2011).

In this study, HPP treatment resulted in a significant $(\mathrm{P}<0.01)$ superficial and deep decrease in Salmonella spp. enumeration varying from 0.61 to $4.01 \mathrm{log}$ and from 1.49 to $4.13 \mathrm{log}$, respectively; the results show that HPP treatment of coppa samples has proven to be effective against both superficial and deep contamination. The generally lower decreases in superficial contamination correlate with the lower $a_{\mathrm{w}}$ values that are proven to have a protective effect on microbial inactivation by HPP (Black et al., 2007; Black et al., 2007; Hayman et al., 2008; Patterson et al., 2005). HPP has demonstrated to be able to reduce Salmonella load in different types of food like raw chicken meat, poultry sausage, RTE meat (Anthoula et al., 2018; Hayman et al., 2004; Lerasle et al., 2014; Tananuwong et. al, 2012; Yuste et a., 2000) and fermented pork sausages (Garriga et al., 2003); in particular in dry-cured ham (Bover-Cid et al., 2017; Garriga et al., 2004): when an HPP treatment of $600 \mathrm{MPa}$ for 5 min was used on artificially contaminated sliced cured ham ( $a_{\mathrm{w}}$ ca 0.92 ), the reduction of $S$. enterica ranged from 3.72 to $5.04 \mathrm{log}$ (Bover-Cid et al., 2017). In general, lower values of microbial reductions during HPP treatment were observed in the present study, but the comparison of this kind of data appears to be problematic as regards the possible differences in the characteristics of the treated products, in experimental design, HPP treatment conditions and baroresistance of the strains used for contamination.

The results of this study confirm that HPP treatment can be successfully used as an effective supplemental intervention strategy for controlling Salmonella spp. contaminations in dry-cured meat products such as coppa. In the case of products intended for exportation to countries with a zero tolerance policy for Salmonella spp., specifically the United States, HPP treatment used as a final sanitization measure after production, resulted to be a determining factor for the achievement of the USDA/FSIS requisites in establishments B, $\mathrm{C}$ and $\mathrm{D}$, resulting particularly relevant in establishment D. According to the data presented in this study, only the combined approach of coppa manufacturing process followed by HPP treatment always led to a $5-\log$ reduction of Salmonella spp. required by USDA/FSIS guidelines. Results suggest that the three establishments B, C, D should review their entire production process (especially for establishment D) either by adding the HPP step or, as additional option, by reviewing the time/temperature of the other decontamination steps of resting, drying and ripening.

\section{References}

Anthoula AA, Papadopoulou OS, Nisiotou A, Tassou CC, Chorianopoulos N, 2018. Effect of high-pressure processing on the survival of Salmonella enteritidis and shelf-life of chicken fillets. Food Microbiol 70, 55-64.

Black EP, Huppertz THM, Kelly AL, Fitzgerald GF, 2007. Baroprotection of vegetative bacteria by milk constituents: a study of Listeria innocua. Int Dairy J 17:104-10.

Black EP, Setlow P, Hocking AD, Stewart CM, Kelly AL, Hoover DG, 2007. Response of spores to high-pressure processing. Compr Rev Food Sci and Food Saf 6:103-19.

Bonilauri P, Grisenti MS, Daminelli P, Merialdi G, Ramini M, Bardasi L, Taddei R, Cosciani-Cunico E, Dalzini E, Frustoli MA, Giacometti F, Piva S, Serraino A. 2019. Reduction of Salmonella spp. populations in Italian salami during production process and High Pressure Processing treatment: validation of processes to export to the U.S. Meat Science 157:107869.

Bover-Cid S, Belletti N, Aymerich T, Garriga M, 2017. Modelling the impact of water activity and fat content of dry-cured ham on the reduction of Salmonella enterica by high pressure processing. Meat Sci 123:120-125.

Busconi M, Zacconi C, Scolari G. 2014. Bacterial ecology of PDO Coppa and Pancetta Piacentina at the end of ripening and after MAP storage of sliced product. Int. J. of Food Microbiol 172:13-20.

European Community. 2005. Commission Regulation (EC) No 2073/2005 of 15 November 2005 on microbiological criteria for foodstuffs.

EFSA, 2010. Management of left-censored data in dietary exposure assessment of chemical substances. EFSA J 8:1557.

FSIS, 2017. Salmonella Compliance Guidelines for Small and Very Small Meat and Poultry Establishments that Produce Ready-to-Eat (RTE) Products and Revised Appendix A June 2017.

Garriga M, Grebol N, Aymerich MT, Monfort JM, Hugas M, 2004. Microbial inactivation after high-pressure processing at $600 \mathrm{MPa}$ in commercial meat products over its shelf life. Innov Food Sci Emerg Technol 5:451-457.

Garriga M, Marcos B, Aymerich T, Hugas M, 2003. Prospectiva de aplicación de altas presiones para la minimización de riesgos asociados a Salmonella y Listeria monocytogenes en embutidos madurados en frío. Eurocarne 121:6.

Hayman MM, Baxter I, O'Riordan PJ, Stewert CM, 2004. Effects of HighPressure Processing on the Safety, Quality, and Shelf Life of Ready-to-Eat Meats. JFP 67:1709-18.

Hayman MM, Kouassi GK, Anantheswaran RC, Floros JD, Knabel SJ, 2008. Effect of water activity on inactivation of Listeria monocytogenes and lactate dehydrogenase during high pressure processing. Int J Food Microbiol 124:216.

Hugas M, Garriga M, Monfort JM, 2002. New mild technologies in meat processing: high pressure as a model technology. Meat Sci 62:359-71.

ISO 21807:2004. Microbiology of food and 
animal feeding stuffs - Determination of water activity.

ISO 6579:2002/Cor1:2004. Microbiology of food and animal feeding stuffs Horizontal method for the detection of Salmonella spp.

Italian Ministry of Health, 2015. Export verso gli USA di prodotti a base di carne: rimosse le misure restrittive.

Lerasle M, Guillou S, Simonin H, Anthoine V, Chéret R, Federighi M, Membré JM, 2014. Assessment of Salmonella and Listeria monocytogenes level in readyto-cook poultry meat: effect of various high-pressure treatments and potassium lactate concentrations. Int $\mathrm{J}$ Food Microbiol 186, 74-83.

Morales-Partera ÁM, Cardoso-Toset F, Jurado-Martos F, Astorga RJ, Huerta B, Luque I, Tarradas C, Gómez-Laguna J, 2017. Survival of selected foodborne pathogens on dry cured pork loins. Int $\mathrm{J}$
Food Microbiol 258:68-72.

Patterson MF, 2005. Microbiology of pressure-treated foods. J Appl Microbiol 98:1400-9.

Pin C, Avendaño-Perez G, Cosciani-Cunico E, Gómez N, Gounadakic A, Nychas GJ, Skandamis P, Barker G, 2011. Modelling Salmonella concentration throughout the pork supply chain by considering growth and survival in fluctuating conditions of temperature, $\mathrm{pH}$ and aw. Int $\mathrm{J}$ Food Microbiol 145:S96-S102.

Reynolds AE, Harrison MA, Rose-Morrow R, Lyon CE, 2001. Validation of dry cured ham process for control of pathogens. J Food Sci 66:1373-9.

Tananuwong K, Chitsakun T, Tattiyakul J, 2012. Effects of high-pressure processing on inactivation of Salmonella Typhimurium, eating quality, and microstructure of raw chicken breast fillets. J of Food Sci 77:E321-7.
Tao Y, Sun D, Hogan E, Kelly AL, 2016. High-Pressure Processing of Foods: An Overview. In: Da-Wen Sun, 2nd ed. Emerging Technologies for Food Processing. Academic Press, pp. 3-24.

Todd ECD, 2004. Microbiological safety standards and public health goals to reduce foodborne disease. Meat Sci $66: 33-43$.

Yuste J, Pla R, Mor-Mur M, 2000. Salmonella enteritidis and aerobic mesophiles in inoculated poultry sausages manufactured with highpressure processing. Lett Appl Microbiol 31:374-7.

Zanardi E, Novelli E, Ghiretti GP, ChizzoliniR. 2000. Oxidative stability of lipids and cholesterol in salame Milano, coppa and Parma ham: dietary supplementation with vitamin $\mathrm{E}$ and oleic acid. Meat Science 55:169-75. 